\title{
Mood changes after indoor tanning among college women: associations with psychiatric/addictive symptoms
}

\author{
Carolyn Heckman, ${ }^{1}$ Susan Darlow, ${ }^{1}$ Jessye Cohen-Filipic, ${ }^{2}$ Jacqueline Kloss ${ }^{3}$ \\ ${ }^{1}$ Cancer Prevention and Control Program, Fox Chase Cancer Center, Philadelphia, PA; \\ ${ }^{2}$ Department of Psychology, Ithaca College, Ithaca, $N Y ;{ }^{3}$ Department of Psychology, Drexel \\ University, Philadelphia, PA, USA
}

\begin{abstract}
Indoor tanning (IT) has been linked with psychiatric and addictive symptoms, and frequent tanning may indicate tanning dependence (addiction). The current study evaluated the effects of an IT episode on mood states and the association of these effects with psychiatric and addictive symptoms among young adult female indoor tanners. One-hundred thirty-nine female university students aged 18-25 years who had indoor tanned completed an online survey including the Positive and Negative Affects Scales and a standardized psychiatric interview (the MINI International Neuropsychiatric Interview) via telephone. Psychiatric and addictive symptoms were relatively com-
\end{abstract}

Correpondence: Carolyn J. Heckman, Cancer Prevention and Control Program, Fox Chase Cancer Center, 333 Cottman Ave., Philadelphia, PA, 19111, USA.

Tel.: +1.215.214.3962 - Fax: +1.215.214.2178.

E-mail: carolyn.heckman@fccc.edu

Key words: Indoor tanning; young adult women; affect; PANAS; psychiatric and addictive symptoms.

Acknowledgments: the authors would like to thank Ms. Sara Filseth and Ms. Elizabeth Culnan for their assistance with recruitment and data collection and Ms. Helene Conway and Ms. Jeanne Pomenti for their administrative assistance with this study and the preparation of this manuscript.

Contributions: $\mathrm{CH}$ and SD had full access to all of the data in the study and take responsibility for the integrity of the data and the accuracy of the data analysis. Study concept and design: CH, SD. Acquisition, analysis, and interpretation of data: all. Drafting of the manuscript: $\mathrm{CH}$, SD. Critical revision of the manuscript for important intellectual content: $\mathrm{CH}, \mathrm{SD}$, JK. Statistical analysis: SD. Obtained funding: CH, SD. Administrative, technical, or material support: all.

Conflict of interest: the authors declare no conflict of interest.

Funding: this work was supported by the National Cancer Institute (R03CA1504202), (T32CA009035), (P30CA006927).

Received for publication: 21 July 2015.

Revision received: 25 February 2016.

Accepted for publication: 26 February 2016.

This work is licensed under a Creative Commons AttributionNonCommercial 4.0 International License (CC BY-NC 4.0).

(C) Copyright C. Heckman et al., 2016

Licensee PAGEPress, Italy

Health Psychology Research 2016; 4:5453

doi:10.4081/hpr.2016.5453 mon among these young adult female indoor tanners. Overall, participants reported significant decreases in both negative (upset, scared, irritable, nervous, jittery, afraid) and positive (feeling interested) mood states after their most recent tanning episode. Multivariable linear regression analyses showed that more frequent indoor tanning in the past month and symptoms of illicit drug use disorders were associated with decreases in negative mood, and symptoms of generalized anxiety disorder were associated with a decrease in feeling interested. In summary, indoor tanners report relatively high rates of psychiatric and substance use symptoms, including symptoms of tanning dependence, and indoor tanning appears to alter mood. Women with certain substance use and psychiatric characteristics may be more vulnerable to such mood changes after tanning indoors. Further research is needed to clarify the relationships among these variables.

\section{Introduction}

Skin cancer is the most common cancer in the USA, with almost five million new cases diagnosed yearly (United States Department of Health and Human Services, 2014). A disturbing increase in the incidence of melanoma among young adult women has been observed recently (Reed et al., 2012; Zhang et al., 2012). Ultraviolet radiation (UV) exposure, such as indoor tanning, is associated with the development of both melanoma and non-melanoma skin cancers (Colantonio, Bracken \& Beecker, 2014; Wehner et al., 2012). Despite attempts to regulate the tanning industry, indoor tanning is a relatively common practice, particularly in the USA and other Western countries. Among US college students, the past year prevalence of indoor tanning ranges from 40 to $60 \%$, with higher rates among female undergraduates (Bagdasarov, Banerjee, Greene, \& Campo, 2008; Hillhouse, Stapleton, \& Turrisi, 2005; Poorsattar \& Hornung, 2007). Many individuals indoor tan despite being aware of the link between UV exposure and skin cancer. Young people may have motives to tan that may outweigh their concerns for their health, with appearance enhancement being the most commonly cited reason given for indoor tanning (Asvat, Cafri, Thompson, \& Jacobsen, 2010; Ingledew, Ferguson, \& Markland, 2010). Emotional effects such as relaxation, enhanced mood, stress relief, and improved energy are other commonly cited reasons for indoor tanning (Feldman et al., 2004; Kourosh, Harrington, \& Adinoff, 2010; Stapleton, Turrisi, Hillhouse, Robinson, Abar, 2010). Young people are also influenced by the indoor tanning behaviors of close others, especially peers (Bagdasarov et al, 2008; Cokkinides, Weinstock, Lazovich, Ward, \& Thun, 2009). Additionally, indoor tanning is associated with psychiatric and addictive symptoms. Indoor tanning is associated with body dysmorphic disorder (Phillips et al., 2006), seasonal affective disorder (Hillhouse et al., 2005), obsessive compulsive tendencies (Leary, Saltzman, \& Georgeson, 1997), and generalized anxiety (Heckman et al., 2014; Mosher \& Danoff-Burg, 2010a, 2010b). Indoor tanners are 
also more likely to use alcohol, cigarettes, steroids (among male adolescents), and other substances (Guy et al., 2014; Heckman et al., 2014; Lostritto et al., 2012; Mosher \& Danoff-Burg, 2010a, 2010b). A phenomenon that has received attention is tanning dependence or addiction, also known as tanorexia. Although tanning dependence in not an official disorder according to the American Psychiatric Association's Diagnostic and Statistical Manual (DSM; American Psychiatric Association, 2013), tanning dependence is defined based on traditional substance dependence criteria and measures (i.e., tolerance, withdrawal, difficulty controlling the behavior despite negative consequences). Some studies have provided evidence for the existence of tanning dependence (Heckman et al., 2014). Tanning dependence rates have been estimated to range from 5 to $45 \%$ among undergraduate indoor tanners and 18\% among college sunbathers (Harrington et al., 2010; Hillhouse, Turrisi, Jaccard, \& Robinson, 2012; Mosher \& DanoffBurg, 2010a, 2010b; Poorsattar, \& Hornung, 2007). Tanning dependent individuals may tan frequently and put themselves at even greater risk of skin cancer than other tanners. UV light exposure leads to production of beta-endorphin, a natural opioid (Feldman et al., 2004; Kaur et al., 2006), which may induce euphoria and analgesia, similar to the effects of recreational drugs.

Most indoor tanners begin indoor tanning as adolescents in an attempt to enhance their appearance or due to peer pressure, despite being aware of the damaging effects of UV (Bagdasarov et al., 2008; Cokkinides et al., 2009). Some of these individuals will not find the experience reinforcing and will not tend to continue tanning either because they do not perceive their appearance to be enhanced or they experience negative consequences such as sunburns. However, consistent with a reinforcer pathology model, a subset of indoor tanners will find the experience reinforcing either due to perceived appearance enhancement or other reinforcing biopsychological effects such as relaxation or improved mood, potentially caused by release of betaendorphin (Feldman et al., 2004; Kaur et al., 2006; Kourosh et al., 2010; Stapleton et al., 2010; Reed, 2015). These reinforcing effects, by definition, make it more likely that such individuals would tan again, whether this link between tanning and improved emotional state is consciously recognized or not. The reinforcing emotional effects of tanning (i.e., increases in positive mood states and decreases in negative mood states) may be more potent among vulnerable individuals with underlying psychiatric problems such as anxiety or mood disorders. Ongoing and/or frequent tanning despite personally experiencing negative consequences such as visible signs of aging suggests powerful motivations such as tanning dependence or self-medication for emotional problems (Hillhouse et al., 2005; Poorsattar \& Hornung, 2007).

The current study involved a survey/interview to evaluate the effects of an indoor tanning episode on mood states and the association of these effects with psychiatric and addictive symptoms among young adult female indoor tanners. It was hypothesized that increases in positive mood states and decreases in negative mood states after indoor tanning would be associated with psychiatric and addictive symptoms. This is the first investigation to include a gold-standard comprehensive standardized psychiatric interview of tanners rather than using a selfreport survey. Identifying emotional and psychosocial characteristics of high risk tanners could facilitate the development of future tailored prevention and intervention efforts to reduce skin cancer risk in these populations.

\section{Materials and Methods}

\section{Participants}

One hundred thirty nine female undergraduates at a northeastern university who had ever indoor tanned completed the survey and psychiatric interview. Participants' ages ranged from 18 to 25 years old $(\mathrm{M}=20.2, \mathrm{SD}=1.7)$. Racial distribution was as follows: $92.8 \%$ White, 2.2\% Asian American, 0.7\% Black, and 4.3\% Other/Mixed. Two percent of the sample identified as Hispanic or Latino. About two thirds of the participants were assessed in the winter and fall, with the remaining third being assessed in the spring.

\section{Measures}

Participants responded to the Positive Affect and Negative Affect Scale (PANAS; Watson, Clark, \& Tellegen, 1988) retrospectively regarding their mood state before and after their most recent indoor tanning session, similar to methods used by Matthews and colleagues for episodes of gambling (Matthews, Farnsworth, \& Griffiths, 2009). The PANAS is a 20 -item scale that consists of emotional adjectives for positive (e.g., interested, proud, determined) and negative affective states (e.g., upset, scared, ashamed). Participants were asked to rate each emotional state separately for before and then after their most recent indoor tanning session on a scale of 1 to $5(1=$ Very slightly or not at all, $3=$ Moderately, $5=$ Extremely). The internal reliability of the PANAS is good with Cronbach's alphas for positive affect being 0.88 and 0.90 for negative affect (for before indoor tanning scores).

The Tanning Pathology Scale (TAPS) was developed by Hillhouse, Turrisi, Stapleton and Robinson (2010) to assess pathological tanning motives associated with tanning dependence. Specifically, perceiving tanning as a problem (e.g., Sometimes I think my tanning is out of control), opiate-like reactions to tanning (e.g., I feel tranquil after a tanning session), tolerance to tanning (Tanning doesn't relieve my stress as well as it did when I started), and dissatisfaction with skin tone (I wish I had been born with a darker shade of skin). TAPS response options utilize a 5 -point Likert-type scale of agreement ( 1 = strongly disagree, 5 = strongly agree). Item responses are summed for each subscale. The TAPS scales are associated with tanning intentions (Hillhouse et al., 2010). In our previous work with college women, we found that the tolerance to tanning subscale had low internal reliability and eigenvalues and was not significantly correlated with measures of tanning attituades and behaviors (Heckman et al., 2014). Therefore, the sum of scores for the remaining subscales were examined for this study. The measure used in this manner is internally consistent in the current sample $(\alpha=0.91)$.

The 15-minute Mini-International International Neuropsychiatric Interview (MINI, version 6.0.0; Lecrubier et al., 1997) was used to assess symptoms of major depression and generalized anxiety disorder, as well as alcohol and illicit substance use disorders. Because few participants met full diagnostic criteria for most of the disorders, participants were classified as meeting screening criteria for each disorder if they reported between one and three key screening symptoms, corresponding with meeting criterion $A$ of the DSM. For example, participants who met screening criteria for generalized anxiety disorder reported being excessively anxious or worried about several routine things most days over the past six month. The MINI standardized clinical interview demonstrates good test-retest reliability, with kappa coefficients ranging from 0.76 to 0.93 (Lecrubier et al., 1997). Kappa coefficients between scores on the MINI and the Composite International Diagnostic Interview, a similar measure, have been found to be acceptable (Lecrubier et al., 1997). The MINI was administered over the telephone, as has been done in prior studies (Lin et al., 2012; Shvartzman et al. 2005), which have reported acceptable reliability but have not made validity data for this modality available.

The Seasonal Scale Index (SSI) was used to assess symptoms of seasonal affective disorder (Rosenthal et al., 1987), which has been found to be associated with indoor tanning (Hillhouse et al., 2005). This brief 
measure, which is a central feature of the Season Pattern Assessment Questionnaire (Rosenthal et al., 1987), prompts respondents to indicate the degree of change that occurs throughout the year for sleep length, social activity, mood, weight, appetite, and energy level. Scores can range from 6 to 24, with a score of 11 or above being considered presence of seasonal affective disorder (Rosenthal et al., 1987). This measure demonstrates good validity (Magnusson, Friis, \& Opjordsmoen, 1997) and was internally consistent in the current study $(\alpha=0.86)$. Participants were asked how many times they had indoor tanned in the past 30 days. Since this variable was skewed, a square root transformation was applied. Participants were asked to indicate how many cigarettes they smoked over the past 30 days and were dichotomized into having smoked or not.

\section{Procedures}

All female psychology students at a northeastern university across six academic terms over two years were invited to participate in the study by e-mail. Psychology 101 is a required course for several majors at the university. After consenting via an online consent form, students completed the questionnaire at their convenience. All scales were completed online except the MINI, which was completed over the telephone with a trained member of the research staff, either a research assistant who had been trained by MINI staff and provided with ongoing supervision or an advanced doctoral counseling psychology student with prior MINI administration experience. Written information about indoor tanning and mental health referrals was offered to all participants. Participants were given research participation extra credit for an academic course and a $\$ 20$ PayPal voucher as compensation for their participation. This study was approved by the university's and a cancer center's Institutional Review Boards.

\section{Data analysis}

First, descriptive statistics were calculated for the study variables, including indoor tanning, psychiatric and substance use disorder symptoms, and symptoms of tanning dependence. Next, paired samples $t$ tests were conducted to examine reported change in positive and negative mood states following an indoor tanning episode. To gain a more complete understanding of changes in mood after indoor tanning, each of the 20 PANAS mood states were examined individually, as opposed to simply looking at change in positive and negative mood. To account for the numerous hypothesis tests, the false discovery rate (FDR) procedure was applied (Benjamini, \& Hochberg, 1995). Multivariable linear regression analyses were conducted to examine associations between psychiatric symptoms, drug use symptoms, and tanning dependence symptoms and reported mood following tanning. The following variables were examined as predictors: smoked in the past 30 days, symptoms of an alcohol use disorder, symptoms of an illicit drug use disorder, meeting criteria for season affective disorder, symptoms of a major depressive episode, generalized anxiety disorder symptoms, and tanning dependence. Reported mood before tanning and having tanned in the past month were controlled for

\section{Results}

See Table 1 for descriptive statistics of study variables.

Paired samples $t$-tests were conducted to examine indoor tanners' reported change in mood states from before to after their most recent indoor tanning episode. Results are reported in Table 2, as well as the adjusted P-value threshold based on the FDR adjustment (i.e., $q$-value). After applying the FDR, the following negative mood states were
Table 1. Characteristics of college female indoor tanners $(\mathrm{N}=139)$.

\section{Variable}

Smoked in past 30 days, N. (\%)*

$31(22.3)$

Alcohol disorder symptoms, N. (\%)*

Illicit drug use disorder symptoms, N. (\%)*

$17(12.2)$

Seasonal affective disorder, N. (\%)*

$70(50.4)$

Major depression symptoms, N. (\%)*

$37(26.6)$

Generalized anxiety symptoms, N. (\%)*

Frequency of indoor tanning in past month (range: $0-5.5), \mathrm{M}(\mathrm{SD})^{\circ} 0.6$ (1.2)

Tanning dependence (range: 15-75), M (SD) $29.8(11.4)$

*Refers to a positive endorsement; ${ }^{\circ}$ Variable is square root transformed.

Table 2. Self-reported mood before and after most recent indoor tanning episode $(\mathrm{N}=139)$.

\begin{tabular}{|c|c|c|c|c|c|}
\hline Item & $\begin{array}{l}\text { Before } \\
\text { and after tanning }\end{array}$ & $M(S D)$ & $\mathrm{t}$ & $\mathbf{P}$ & q value \\
\hline Interested* & $\begin{array}{l}\text { Before } \\
\text { After }\end{array}$ & $\begin{array}{l}3.1(1.0) \\
2.8(1.0)\end{array}$ & 4.91 & $<0.001$ & 0.0025 \\
\hline Disinterested & $\begin{array}{l}\text { Before } \\
\text { After }\end{array}$ & $\begin{array}{l}1.9(1.0) \\
1.8(1.1)\end{array}$ & 2.14 & 0.034 & 0.0225 \\
\hline Excited & $\begin{array}{l}\text { Before } \\
\text { After }\end{array}$ & $\begin{array}{l}2.9(1.1) \\
2.9(1.2)\end{array}$ & -0.08 & 0.934 & $\mathrm{NA}$ \\
\hline Upset* & $\begin{array}{l}\text { Before } \\
\text { After }\end{array}$ & $\begin{array}{l}1.6(0.9) \\
1.4(0.8)\end{array}$ & 3.38 & 0.001 & 0.0075 \\
\hline Strong & $\begin{array}{l}\text { Before } \\
\text { After }\end{array}$ & $\begin{array}{l}2.4(1.1) \\
2.3(1.2)\end{array}$ & 0.66 & 0.513 & NA \\
\hline Guilty & $\begin{array}{l}\text { Before } \\
\text { After }\end{array}$ & $\begin{array}{l}1.9(1.0) \\
1.8(1.0)\end{array}$ & 0.61 & 0.543 & NA \\
\hline Scared* & $\begin{array}{l}\text { Before } \\
\text { After }\end{array}$ & $\begin{array}{l}1.6(1.0) \\
1.4(0.9)\end{array}$ & 3.28 & 0.001 & 0.0075 \\
\hline Hostile & $\begin{array}{l}\text { Before } \\
\text { After }\end{array}$ & $\begin{array}{l}1.3(0.7) \\
1.3(0.7)\end{array}$ & 0.23 & 0.820 & $\mathrm{NA}$ \\
\hline Enthusiastic & $\begin{array}{l}\text { Before } \\
\text { After }\end{array}$ & $\begin{array}{l}2.7(1.0) \\
2.6(1.2)\end{array}$ & 1.44 & 0.152 & NA \\
\hline Proud & $\begin{array}{l}\text { Before } \\
\text { After }\end{array}$ & $\begin{array}{l}2.2(1.1) \\
2.3(1.2)\end{array}$ & -1.20 & 0.234 & NA \\
\hline Irritable* & $\begin{array}{l}\text { Before } \\
\text { After }\end{array}$ & $\begin{array}{l}1.6(1.0) \\
1.4(0.8)\end{array}$ & 3.38 & 0.001 & 0.0075 \\
\hline Alert & $\begin{array}{l}\text { Before } \\
\text { After }\end{array}$ & $\begin{array}{l}2.4(1.2) \\
2.2(1.2)\end{array}$ & 2.17 & 0.032 & 0.02 \\
\hline Ashamed & $\begin{array}{l}\text { Before } \\
\text { After }\end{array}$ & $\begin{array}{l}1.5(0.9) \\
1.5(0.9)\end{array}$ & 0.95 & 0.345 & $\mathrm{NA}$ \\
\hline Inspired & $\begin{array}{l}\text { Before } \\
\text { After }\end{array}$ & $\begin{array}{l}1.9(1.1) \\
2.0(1.2)\end{array}$ & -1.57 & 0.118 & NA \\
\hline Nervous* & $\begin{array}{l}\text { Before } \\
\text { After }\end{array}$ & $\begin{array}{l}1.9(1.1) \\
1.4(0.8)\end{array}$ & 5.68 & $<0.001$ & 0.0025 \\
\hline Determined & $\begin{array}{l}\text { Before } \\
\text { After }\end{array}$ & $\begin{array}{l}2.3(1.2) \\
2.2(1.2)\end{array}$ & 1.78 & 0.077 & NA \\
\hline Attentive & $\begin{array}{l}\text { Before } \\
\text { After }\end{array}$ & $\begin{array}{l}2.4(1.1) \\
2.3(1.2)\end{array}$ & 1.71 & 0.089 & NA \\
\hline Jittery* & $\begin{array}{l}\text { Before } \\
\text { After }\end{array}$ & $\begin{array}{l}1.7(1.0) \\
1.5(0.9)\end{array}$ & 3.00 & 0.003 & 0.015 \\
\hline Active & $\begin{array}{l}\text { Before } \\
\text { After }\end{array}$ & $\begin{array}{l}2.5(1.2) \\
2.5(1.3)\end{array}$ & -0.17 & 0.866 & NA \\
\hline Afraid* & $\begin{array}{l}\text { Before } \\
\text { After }\end{array}$ & $\begin{array}{l}1.6(1.0) \\
1.4(0.9)\end{array}$ & 2.71 & 0.008 & 0.0175 \\
\hline
\end{tabular}

*Mood states with significant values, based on the adjusted threshold. 
reported to significantly decrease after an indoor tanning episode: upset, $t(133)=3.38, \mathrm{P}<0.01$, scared, $t(133)=3.28, \mathrm{P}<0.01$, irritable, $t(133)=3.38, \quad \mathrm{P}<0.01$, nervous, $t(132)=5.68, \quad \mathrm{P}<0.001$, jittery, $t(133)=3.00, \mathrm{P}<0.01$, and afraid, $t(132)=2.71, \mathrm{P}<0.01$. The only positive mood state that subjects reported significantly changing was interested, $t(134)=4.91, \mathrm{P}<0.001$ (Table 3 ).

Two multivariable linear regression models were conducted: one examining the positive mood state of how interested participants felt after an indoor tanning session, and another model examining negative mood states following indoor tanning; specifically, the negative mood states that participants reported significantly changing after indoor tanning (i.e., upset, scared, irritable, nervous, jittery, afraid). Negative mood after indoor tanning was positively associated with negative mood before tanning, $t(119)=14.30, \mathrm{P}<0.001$, and negatively associated with frequency of indoor tanning in the past month, $t(119)=-2.74, \mathrm{P}<0.01$, and illicit drug use, $t(119)=-2.49, \mathrm{P}<0.05$. Reported feelings of interest after indoor tanning were positively associated with feeling interested before indoor tanning, $t(119)=8.80$, $\mathrm{P}<0.001$, and generalized anxiety, $t(119)=2.21, \mathrm{P}<0.05$.

\section{Discussion and Conclusions}

Prior survey studies have demonstrated the association of indoor tanning and tanning dependence with various other psychiatric and substance use symptoms (Bagdasarov et al., 2008; Heckman et al., 2014; Lostritto et al., 2012; Mosher \& Danoff-Burg, 2010a, 2010b). However, this is the first study to investigate indoor tanning and tanning dependence in the context of a standardized psychiatric interview. Relatively high rates of psychiatric and addictive disorders and symptoms among these young adult female indoor tanners were reported. For example, almost $40 \%$ met criteria for tanning dependence, over $50 \%$ met criteria for seasonal affective disorder, and over $70 \%$ reported drinking at least three alcoholic drinks in a three hour period at least three times in the past year.

Not only did negative mood states (upset, irritable, nervous) decrease among young adult female indoor tanners after their most recent indoor tanning episode, but contrary to hypotheses, positive mood state of feeling interested did as well. These mood states decreased a small, albeit significant, amount. Women whose negative mood decreased after indoor tanning were more likely to be more frequent indoor tanners. Indoor tanners report that decreased negative

Table 3. Associations between psychiatric and addictive symptoms and reported mood after indoor tanning $(\mathrm{N}=139)$.

\begin{tabular}{lcccc} 
Variable & $\begin{array}{c}\text { Negative }^{2} \\
\text { B }\end{array}$ & SE & \multicolumn{2}{c}{ Interested } \\
B & SE \\
Mood before tanning & $0.75^{* * *}$ & 0.05 & $0.69^{* * *}$ & 0.08 \\
Indoor tanning in past month & $-0.10^{* *}$ & 0.04 & 0.07 & 0.07 \\
\hline Smoked in past 30 days & 0.03 & 0.09 & -0.10 & 0.17 \\
Alcohol use & 0.11 & 0.09 & -0.03 & 0.16 \\
\hline Illicit drug use (+ marijuana) & $-0.29^{*}$ & 0.12 & 0.22 & 0.22 \\
Seasonal affective & 0.06 & 0.08 & -0.01 & 0.15 \\
\hline Major depressive & 0.10 & 0.09 & -0.02 & 0.17 \\
Generalized anxiety & -0.04 & 0.10 & $0.40^{*}$ & 0.18 \\
\hline Tanning dependence & 0.01 & 0.00 & 0.00 & 0.01 \\
\hline
\end{tabular}

${ }^{*} \mathrm{P}<0.05 ;{ }^{*} \mathrm{P}<0.01 ;{ }^{* * *} \mathrm{P}<0.001$; a Upset, scared, irritable, nervous, jittery, afraid. mood is one of the reasons they indoor tan (Feldman et al., 2004; Kourosh et al., 2010; Stapleton et al., 2010). The only prior study to use the PANAS to assess the effects of indoor tanning on mood found significantly higher scores on the relaxation and lower scores on the tension item among 14 frequent indoor tanning females after indoor UVlight compared to non UV-light tanning (Feldman et al., 2004).

Regarding the association of psychiatric and addictive symptoms with changes in mood states after tanning, a decrease in negative mood states was associated with symptoms of an illegal drug use disorder as hypothesized but not symptoms of tanning dependence. Consistent with a reinforcer pathology model (Reed, 2015), it is possible that some women may use indoor tanning in a manner similar to recreational drugs in order to attempt to decrease negative mood states such as feeling upset, irritable, or nervous. The lack of association with symptoms of tanning dependence may indicate that individuals who are dependent on tanning no longer receive the mood enhancing benefits of tanning but continue to tan anyway, a hallmark of substance dependence. Symptoms of generalized anxiety disorder were associated with a decrease in feeling interested. This finding is contrary to hypotheses. One possibility is that anxious women who indoor tan may be hyper-aroused and be seeking a feeling of emotional numbness in which even positive feelings become less intense. Prior studies have found indoor tanning to be associated with illicit drug use, anxiety, and the desire to reduce negative mood (Feldman et al., 2004; Heckman et al., 2014; Kourosh et al., 2010; Lostritto et al., 2012; Mosher \& DanoffBurg, 2010a, 2010b; Poorsattar, \& Hornung, 2007; Stapleton et al., 2010).

Negative affect is associated with symptoms of anxiety and depression. Several studies have examined changes in PANAS scores after engaging in behaviors such as smoking, exercising, and gambling and compared these changes in individuals with psychiatric and addictive symptoms to others (Lepage \& Crowther, 2010; Matthews et al., 2009; Spring et al., 2008). Similar to the current findings for indoor tanning, negative affect decreases after smoking and exercising, particularly among individuals with psychiatric symptoms such as individuals vulnerable to depression and with high body dissatisfaction, respectively (Lepage \& Crowther, 2010; Spring et al., 2008). However, college problem gamblers reported an increase in negative affect after gambling compared to before or during gambling (Matthews et al., 2009). Interestingly, findings for changes in positive affect have been inconsistent among both general samples and individuals with specific psychiatric and addictive symptoms (Lepage \& Crowther, 2010; Matthews et al., 2009; Spring et al., 2008).

A strength of the current study is its use of a well-validated comprehensive standardized psychiatric interview, which has never been done before with this population despite prior evidence of psychiatric symptomatology. Prior research had used questionnaires and non-standardized interviews that have focused on circumscribed symptoms such as anxiety or depression. Recruitment and surveys were completed online for the current study. Prior studies have demonstrated similar participation rates and demographic characteristics of online research participants compared with traditional recruitment and data collection methods (Gardner et al., 1996; West et al., 2006). Online data collection also allows one to automate data quality procedures (e.g., response logic). One study limitations is the use of a convenience sample, which may affect the generalizability of the results. Although this study was conducted with a primarily white sample at only one university, white college women are frequent indoor tanners and are an appropriate high risk study population (Poorsattar, \& Hornung, 2007). Another limitation is the retrospective assessment of emotional states, which is subject to recall bias. For example, less than one third of the sample reported tanning in the past month. Therefore, recalling mood before and after their most recent tanning session may have been challenging. 
The use of prospective data could be informative in this regard. Finally, a measure more sensitive to sub-syndromal psychopathology than the MINI might further clarify the relationships among tanning, emotional states, and symptomatology.

In summary, female college indoor tanners report relatively high rates of psychiatric and substance use symptoms, including symptoms of tanning dependence, and indoor tanning appears to alter mood. The hypotheses were partially borne-out. Indoor tanning was associated with a decrease in negative mood states but also a decrease in feeling interested. Additionally, changes in mood were associated with symptoms of illicit drug use and generalized anxiety disorder. The current study does not reveal whether indoor tanners tan to consciously alter their mood or whether such mood alteration may be better explained by tanning dependence, self-medication of psychiatric symptoms, or other factors. Ideally, prospective research is needed to clarify these relationships by assessing mood before and after tanning sessions rather than retrospectively. However, these findings suggest that clinicians should assess and address not only tanners' increased risk for skin cancer but also their mental and emotional health.

\section{References}

American Psychiatric Association. (2013). Diagnostic and statistical manual of mental disorders. 5th ed. Washington, DC: American Psychiatric Association.

Asvat, Y., Cafri, G., Thompson, J.K., \& Jacobsen, P.B. (2010). Appearance-based tanning motives, sunbathing intentions, and sun protection intentions in adolescents. Archives of dermatology, $146,445-446$.

Bagdasarov, Z., Banerjee, S., Greene, K., \& Campo, S. (2008). Indoor tanning and problem behavior. Journal of American college health, $56,555-561$.

Benjamini, Y., \& Hochberg, Y. (1995). Controlling the false discovery rate: a practical and powerful approach to multiple testing. Journal of the Royal Statistical Society: Series B, 57, 289-300.

Cokkinides, V., Weinstock, M., Lazovich, D., Ward, E., \& Thun, M. (2009). Indoor tanning use among adolescents in the US, 1998 to 2004. Cancer, 115, 190-198.

Colantonio, S., Bracken, M.B., \& Beecker, J. (2014). The association of indoor tanning and melanoma in adults: systematic review and meta-analysis. Journal of the American academy of dermatology, 70, 847-857.

Feldman, S.R., Liguori, A., Kucenic, M., Rapp, S.R., Fleischer, A.B. Jr, Lang, W, \& Kaur, M. (2004). Ultraviolet exposure is a reinforcing stimulus in frequent indoor tanners. Journal of the American academy of dermatology, 51, 45-51.

Gardner, J.S., Szpunar, C.A., 0’Connell, M.J., Facklam, D.P., Mariano, J.P., Borden, E.K., \& Leinweber, F.B. (1996). Cohort maintenance and comparability in a pharmacoepidemiologic study using a commercial consumer panel to recruit comparators. Pharmacoepidemiology and drug safety, 5, 207-214.

Guy, G.P. Jr., Berkowitz, Z., Tai, E., Holman, D.M., Everett Jones, S., \& Richardson, L.C. (2014). Indoor tanning among high school students in the United States, 2009 and 2011. JAMA Dermatology, 150, 501-511.

Harrington, C.R., Beswick, T.C., Leitenberger, J., Minhajuddin, A., Jacobe, H.T., \& Adinoff, B. (2010). Addictive-like behaviours to ultraviolet light among frequent indoor tanners. Clinical and experimental dermatology, 36, 33-38.

Heckman, C.J., Cohen-Filipic, J., Darlow, S., Kloss, J.D., Manne, S.L., \& Munshi, T. (2014). Psychiatric and addictive symptoms of young adult female indoor tanners. American journal of health promotion: AJHP, 28, 168-174.

Heckman, C.J., Darlow, S., Kloss, J.D., Cohen-Filipic, J., Manne, S.L., Munshi, T., ..., Perlis, C. (2014). Measurement of tanning dependence. Journal of the European Academy of Dermatology and Venereology: JEADV, 28, 1179-1185.

Hillhouse, J., Stapleton, J., \& Turrisi, R. (2005). Association of frequent indoor UV tanning with seasonal affective disorder. Archives of dermatology, 141, 1465.

Hillhouse, J., Turrisi, R., Jaccard, J., \& Robinson, J. (2012). Accuracy of self-reported sun exposure and sun protection behavior. Prevention science: the official journal of the Society for Prevention Research, $13,519-531$.

Hillhouse, J., Turrisi, R., Stapleton, J., \& Robinson, J. (2010). Effect of seasonal affective disorder and pathological tanning motives on efficacy of an appearance-focused intervention to prevent skin cancer. Archives of dermatology, 146, 485-491.

Ingledew, D.K., Ferguson, E., \& Markland, D. (2010). Motives and sunrelated behaviour. Journal of health psychology, 15, 8-20.

Kaur, M., Liguori, A., Lang, W., Rapp, S.R., Fleischer, A.B. Jr, \& Feldman, S.R. (2006). Induction of withdrawal-like symptoms in a small randomized, controlled trial of opioid blockade in frequent tanners. Journal of the American academy of dermatology, 54, 709-711.

Kourosh, A.S., Harrington, C.R., \& Adinoff, B. (2010). Tanning as a behavioral addiction. American journal of drug and alcohol abuse, $36,284-290$.

Leary, M.R., Saltzman, J.L., \& Georgeson, J.C. (1997). Appearance motivation, obsessive-compulsive tendencies and excessive suntanning in a community sample. Journal of health psychology, 2, 493499.

Lecrubier, Y., Sheehan, D.V., Weiller, E., Amorim, P., Bonora, I., Harnett Sheehan, K., ..., Dunbar G.C. (1997). The Mini INternational Neuropsychiatric Interview (MINI). A short diagnostic structed interview:reliability and validity according to the CIDI. European psychiatry, 12, 224-231.

Lepage, M.L., \& Crowther, J.H. (2010). The effects of exercise on body satisfaction and affect. Body image, 7, 124-130.

Lin, K.H., Guo, N.W., Liao, S.C., Kuo, C.Y., Hu, P.Y., Hsu, J.H., ..., Guo, Y.L. (2012). Psychological outcome of injured workers at 3 months after occupational injury requiring hospitalization in Taiwan. Journal of occupational health, 54, 289-298.

Lostritto, K., Ferrucci, L.M., Cartmel, B., Leffell, D.J., Molinaro, A.M., Bale, A.E., \& Mayne, S.T. (2012). Lifetime history of indoor tanning in young people: a retrospective assessment of initiation, persistence, and correlates. BMC public health, 12, 118.

Magnusson, A., Friis, S., \& Opjordsmoen, S. (1997). Internal consistency of the Seasonal Pattern Assessment Questionnaire (SPAQ). Journal of Affective Disorders, 42, 113-116.

Matthews, N., Farnsworth, B., \& Griffiths, M.D. (2009). A pilot study of problem gambling among student online gamblers: mood states as predictors of problematic behavior. Cyberpsychology \& Behavior 12, 741-745.

Mosher, C.E., \& Danoff-Burg, S. (2010a). Addiction to indoor tanning: relation to anxiety, depression, and substance use. Archives of dermatololgy, 146, 412-417.

Mosher, C.E., \& Danoff-Burg, S. (2010b). Indoor tanning, mental health, and substance use among college students: the significance of gender. Journal of health psychology, 15, 819-827.

Phillips, K.A., Conroy, M., Dufresne, R.G., Menard, W., Didie, E.R., Hunter-Yates, J., ..., \& Pagano, M. (2006). Tanning in body dysmorphic disorder. Psychiatric quarterly, 77, 129-138.

Poorsattar, S.P., \& Hornung, R.L. (2007). UV light abuse and high-risk tanning behavior among undergraduate college students. Journal 
of the American academy of dermatology, 56, 375-379.

Reed, D.D. (2015). Ultra-violet indoor tanning addiction: a reinforcer pathology interpretation. Addictive Behaviors, 41, 247-251.

Reed, K.B., Brewer, J.D., Lohse, C.M., Bringe, K.E., Pruitt, C.N., \& Gibson, L.E. (2012). Increasing incidence of melanoma among young adults: an epidemiological study in Olmsted County, Minnesota. Mayo Clin Proceedings, 87, 328-334.

Rosenthal, N.E., Genhart, M.J., Sack, D.A., Skwerer, R.G., \& Wehr, T.A. (1987). Seasonal affective disorder and its relevance for the understanding and treatment of bulimia. In: J.I. Hudson, H.G. Pope (Eds), The psychology of bulimia (pp 205-228). Washington, DC: American Psychiatric Press.

Shvartzman, P., Weiner, Z., Vardy, D., Friger, M., Sherf, M., \& Biderman, A. (2005). Health services utilization by depressive patients identified by the MINI questionnaire in a primary care setting. Scandinavian Journal of Primary Health Care, 23, 18-25.

Spring, B., Cook, J.W., Appelhans, B., Maloney, A., Richmond, M., Vaughn, J., ..., Hedeker, D. (2008). Nicotine effects on affective response in depression-prone smokers. Psychopharmacology (Berl), 196, 461-471.

Stapleton, J., Turrisi, R., Hillhouse, J., Robinson, J.K., \& Abar, B. (2010). A comparison of the efficacy of an appearance-focused skin cancer intervention within indoor tanner subgroups identified by latent profile analysis. Journal of behavioral medicine, 33, 181-190.

United States Department of Health and Human Services. (2014). The Surgeon General's Call to Action to Prevent Skin Cancer. Washington, DC: United States Department of Health and Human Services.

Watson, D., Clark, L.A., \& Tellegen, A. (1988). Development and validation of brief measures of positive and negative affect: the PANAS scales. Journal of personality and social psychology, 54, 1063-1070.

Wehner, M.R., Shive, M.L., Chren, M.M., Han, J., Qureshi A.A., \& Linos E. (2012). Indoor tanning and non-melanoma skin cancer: systematic review and meta-analysis. B British medical journal, 345, e5909.

West, R., Gilsenan, A., Coste, F., Zhou, X., Brouard, R., Nonnemaker, J., ..., Sullivan, S.D. (2006). The ATTEMPT cohort: a multi-national longitudinal study of predictors, patterns and consequences of smoking cessation; introduction and evaluation of internet recruitment and data collection methods. Addiction, 101, 1352-1361.

Zhang, M., Qureshi, A.Z., Geller, A.C., Frazier, L., Hunter, D.J., \& Han, J. (2012). Use of tanning beds and incidence of skin cancer. Journal of Clinical Oncology, 30, 1588-1593. 